\title{
Research on evaluating water resource resilience based on projection pursuit classification model
}

\author{
Dong Liu $\cdot$ Dan Zhao $\cdot$ Xu Liang $\cdot$ Qiuchen Wu
}

Received: 10 January 2014/ Accepted: 28 April 2014/Published online: 27 May 2014

(C) The Author(s) 2014. This article is published with open access at Springerlink.com

\begin{abstract}
Water is a fundamental natural resource while agriculture water guarantees the grain output, which shows that the utilization and management of water resource have a significant practical meaning. Regional agricultural water resource system features with unpredictable, self-organization, and non-linear which lays a certain difficulty on the evaluation of regional agriculture water resource resilience. The current research on water resource resilience remains to focus on qualitative analysis and the quantitative analysis is still in the primary stage, thus, according to the above issues, projection pursuit classification model is brought forward. With the help of artificial fish-swarm
\end{abstract}

D. Liu $(\bowtie) \cdot$ D. Zhao $\cdot$ X. Liang $\cdot$ Q. Wu

School of Water Conservancy and Civil Engineering, Northeast Agricultural University, Harbin 150030, Heilongjiang, China

e-mail: liudong5511@ sina.com

D. Zhao

e-mail: dandanzhao_love@163.com

X. Liang

e-mail: 1x19891030@126.com

Q. Wu

e-mail: wu_qiuchen@126.com

D. Liu $\cdot$ D. Zhao $\cdot$ X. Liang $\cdot$ Q. Wu

Key Laboratory of Water-Saving Agriculture of Universities in Heilongjiang Province, Northeast Agricultural University,

Harbin 150030, Heilongjiang, China

D. Liu $\cdot$ D. Zhao $\cdot$ X. Liang $\cdot$ Q. Wu

Collaborative Innovation Center for Improving Grain Production Capacity of Heilongjiang Province, Northeast Agricultural University, Harbin 150030, Heilongjiang, China

D. Liu $\cdot$ D. Zhao $\cdot$ X. Liang $\cdot$ Q. Wu

Key Laboratory of High Efficient Utilization of Agricultural

Water Resource of Ministry of Agriculture, Northeast

Agricultural University, Harbin 150030, Heilongjiang, China algorithm (AFSA), it optimizes the projection index function, seeks for the optimal projection direction, and improves AFSA with the application of self-adaptive artificial fish step and crowding factor. Taking Hongxinglong Administration of Heilongjiang as the research base and on the basis of improving AFSA, it established the evaluation of projection pursuit classification model to agriculture water resource system resilience besides the proceeding analysis of projection pursuit classification model on accelerating genetic algorithm. The research shows that the water resource resilience of Hongxinglong is the best than Raohe Farm, and the last 597 Farm. And the further analysis shows that the key driving factors influencing agricultural water resource resilience are precipitation and agriculture water consumption. The research result reveals the restoring situation of the local water resource system, providing foundation for agriculture water resource management.

Keywords Hongxinglong administration - Projection pursuit classification model - Artificial fish-swarm algorithm - Water resource system resilience

\section{Introduction}

With the rapid growth of population and fast development of economy, the agricultural water supply and demand contradiction are increasing, resulting in a series of ecological and environmental problems, such as water pollution, falling of groundwater level, and obvious deterioration of regional agricultural water resource system. Therefore, the further study on regional agricultural water resource system resilience is the key for scientific utilization of water resource management. Holling (1973) 
creatively introduced resilience into the ecosystem stability and then the resilience research has been gradually recognized and accepted. The resilience mainly applied in the field of disaster (Shang et al. 2011; Manfredi et al. 2014); social ecology (Wang 2008; Perz et al. 2013) and economic management behavior (Comfort 1994). Vergano and Nunes (2007) established conceptual framework to recognize and describe resilience components from the economic perspective, taking the Venetian Lagoon as an example to make empirical assessment of the economic losses from the flood; Chang et al. (2013) took several US Columbia Rivers as example to study and analyze the vulnerability of their water resource with various ecological physical and social economic index representing water supply, water demand, and water quality. The resilience has been introduced into water resource field since the beginning of this century. Although Yu (2007) made evaluation of water resource resilience for Shanxi Province on the basis of raising the concept of water resource resilience and its features, there are still relatively few research articles on regional agricultural water resource resilience. At present, the research on water resource system resilience in and abroad remains in the model of conceptual level and case analysis; the study on resilience diagnosis method is still weak, and the resilience formation mechanism and influencing factor study are still in shortage, and the practical guiding from resilience diagnosis result still needs to be strengthened.

Resilience evaluation methods mainly are MSE decision comprehensive index (Shang et al. 2011), analytic hierarchy process (Sun et al. 2011), fuzzy mathematics comprehensive evaluation (Zhao 2009), and variation coefficient method (Chen and Duan 2010). However, there are certain defects of the traditional evaluation method, which can easily generate problems including evaluation grading discretion, unreasonable results and subjective information factor missing (Fu 2006). Projection pursuit classification model (PPC) is a kind of statistics for highdimensional data processing and analysis and its main thought is to project the high-dimensional data to lowdimensional space and reflect projection value of highdimensional data structure or feature by low-dimensional space. Actually projection pursuit classification model is a dimensional reduction technology, with optimizing projection index function and finding optimal projection value as its core problem. The previous research optimized the projection index function through utilizing real-coded accelerating genetic algorithm (Zhao et al. 2007), particle swarm algorithm (Jiang et al. 2011), immune evolutionary algorithm (Shu et al. 2004), and simulated genetic returns algorithm (Xie et al. 2005) which were uncertain and easy to be caught in partial optima thus to cause unreasonable and unreliable calculating result. This paper tries to apply for AFSA to optimize projection pursuit, introducing selfadaptive artificial fish step and crowding factor to improve AFSA and overcome the defect of being caught in partial optima. Taking Hongxinglong Administration as the research base, it applies for projection pursuit classification model on adaptive artificial fish-swarm algorithm (AAFSA-PPC) to evaluate the resilience of regional agricultural water resource system, and thus to provide a scientific and reasonable research mode for water resource system resilience research.

The target of this paper is to apply AFSA and accelerating genetic algorithm for evaluation on agricultural water resource system resilience of Hongxinglong Administration in Heilongjiang Province, reveal the local water resource resilience condition, and analyze the main driving factor influencing water resource resilience and bring forward improvement suggestion. The first part of the paper is brief introduction, the second part is research method and models including AAFSA, RAGA and PPC, the third part is the case study including research area, data collection and evaluation grading, and the calculation result and discussion, and the final part is the summary and the further study direction.

\section{Methods and models}

\section{Adaptive artificial fish-swarm algorithm}

Artificial fish-swarm algorithm (AFSA) is a random searching optimization algorithm from partial optimization and entire optimization that simulates the actual movement and gathering and other behavior of fish to construct artificial fish, which change its own location from foraging, gathering and rear-end behavior (Mehdi et al. 2012; Ding et al. 2010). This algorithm requires little for the initial value ( $\mathrm{Li} 2003$ ), can randomly generate initial value, does not need to understand the particularity of the problem, and has a more rapid convergence rate (Zhong and Li 2012). However, there are a certain defects during the actual application: (1) the increased artificial fish quantity may cause the increasing of storage space and calculation; (2) if the optimization field is flat, partial of the artificial fish will be in aimless random movement which slows down the calculation convergence rate; (3) the larger the step of artificial fish, the faster the convergence rate, and the easier the partial optimization will be; the smaller the crowding factor, the faster convergence rate, and the easier the partial extreme will be (Ding et al. 2010). In response to the above-mentioned defects, the paper applies for improved AFSA with self-adaptive changing step and crowding 
factor $(\delta)$ to reach optimization through animal homemade body model, in which $\operatorname{step}_{i+1}=\left[\frac{1}{2}+\frac{1}{k}\right] \operatorname{step}_{i}$ and $\delta_{k+1}=$ $1.1 \delta_{k}, k$ means iteration, and $0<\delta<1$. On the basis of this optimization method, the adaptive artificial fish swarm optimization procedure is as follow:

1. Initialization fish swarm: randomly produces $N$ pieces of artificial fish within the scope of the $0-1$, set initial parameters of perception as Visible, the movement initial step as Step, the initial crowding factor as $\delta$, and the maximum training times as try number;

2. Given the bulletin board initial value: put the initial fish swarm into the target function, choose the maximum value as the initial value of bulletin board, and make records about the current artificial fish condition;

3. Behavior selection: start rear-end and gathering behavior and choose to implement the best behavior through the comparison of target function value, and the default is foraging behavior.

(1) Foraging behavior: the current situation of artificial fish is $x_{i}$ and randomly choose a situation $x_{j}$ within the visible field, then if $y_{i} \leq y_{j}$, step forward one step in the current direction; otherwise, reselect the random selection situation $x_{j}$, decide whether satisfy the requirement of stepping forward; after trying try number and still do not satisfy the forward requirement, then randomly move one step;

(2) Cluster behavior: the current situation of artificial fish is $x_{i}$, set the quantity of partner $n_{f}$ in the visible area, and forms a set $K: K=\left\{x_{j} / x_{j}-x_{i} \leq\right.$ visual $\}$, if $\mathrm{K}$ is not an empty set, it shows there is a certain number of partners in the visible field that is $n_{f} \geq 1$, then based on the pursuit center position $X_{c}: x_{c}=\sum_{j}^{n_{f}} x_{f} / n_{f}\left(X_{c}\right.$ means the condition of the center position). If $n_{f} / n<\delta,(0<\delta<1)$, then it shows that there are much foods in the center of partners and not crowded, and if now $y_{i}<y_{c}$, then the artificial fish step forward with one step to the center position $X_{c}$; otherwise, implement foraging behavior;

(3) Rear-end behavior: Exploring the optimal state neighbor $x_{\max }$ within the territory of every artificial fish, it indicates that there are more foods and not too crowded around $x_{\max }$ and the artificial fish goes forward one step to the center position of $x_{\max }$ if $y_{i}<y_{\max }$ and $n_{f} / n<\delta$, $(0<\delta<1)$ within territory of $x_{\max }$. Otherwise foraging behavior will be done.

(4) Updating bulletin board: If the current state of each artificial fish is better than the value of bulletin board after each action, bulletin board is replaced by its own state.

(5) Terminal condition: repeat steps (3) and (4), and do not terminate until the optimal value on the bulletin board reaches the range of satisfied deviation.
Real-coded accelerating genetic algorithm

The real-coded accelerating genetic algorithm (RAGA) is mainly the numerical optimization algorithm that simulates the biological survival of the fittest and group internal chromosomes information exchange mechanism (Fu 2006), which overcomes the defect of partial optima and is in favor of seeking the real optimal solution with high accuracy and fast convergence rate.

\section{Projection pursuit classification model}

Projection Pursuit Classification Model (PPC) can achieve high-dimensional data dimension reduction operation and conduct integrated evaluation for data in low-dimensional space without limitation from problem scale and data structure. The construction procedure of PPC model is as follow (Fu 2006; Chang and Zhao 2013; Friedman and Tukey 1974):

Step 1: The normalization processing of sample evaluation index set. Supposing that sample sets are $\left\{x^{*}(i, j) \mid i=\right.$ $1 \sim n, j=1 \sim p.\}, x^{*}(i, j)$ is parameter value $j$ of sample $i, n$ and $p$ are capacities of sample and quantity of index, respectively. Aiming to eliminate dimension and unify range of variation, it can be normalized as the following:

$x(i, j)=\frac{x^{*}(i, j)-x_{\min }(j)}{x_{\max }(j)-x_{\min }(j)}$

where $x_{\max }(j)$ and $x_{\min }(j)$ are the maximum and the minimum value of $j . x(i, j)$ is the normalized sequence.

Step 2: Construct the projection index function $Q(a)$. The core thought is compressing the $p d$ data into onedimensional projection value $a=\{a(1), a(2), a(3), \cdots$, $a(p)\}$ on the direction $z(i)$.

$z(i)=\sum_{j=1}^{p} a(j) x(i, j)(i=1 \sim n)$

Where $a$ is unit length of the vector. Characteristics of $z(i)$ are that local projection points should gather as much as possible, projection index function could be expressed as following:

$Q(a)=S_{z} D_{z}$

where $S_{z}$ is standard deviation of projection value $z(i), D_{z}$ is local density of projection value $z(i)$.

Step 3: Optimize the projection objective function.

The maximal objective function:

$\operatorname{Max}: Q(a)=S_{z} \cdot D_{z}$

The constraint condition

s.t : $\sum_{j=1}^{p} a^{2}(j)=1$ 


\section{Application}

Study area

Hongxinglong Administration is located at the south central of Sanjiang Plain in Heilongjiang province with its geographic coordinates as longitude $129^{\circ} 55^{\prime}-134^{\circ} 12^{\prime} \mathrm{E}$ and latitude $45^{\circ} 35^{\prime}-47^{\circ} 17^{\prime} \mathrm{N}$. The region is east to the Wusuli River, with Russia in the opposite bank, west to the Weiken River, south to Wandashan Mountain, north to the Songhua River and Raoli River. The rainfall is rich while the land fertile. The authority owns 12 large and medium-sized state-owned modern farms (Fig. 1). The proportion of area under administration is $9,650 \mathrm{~km}^{2}$, which is the milli of national territorial area. Hongxinglong Administration is an important commodity grain base and organic food base in China. It takes on two crucial leading missions that are propelling roundly construction of national modern agriculture demonstration zone and integrating urban and rural. To achieve the provincial strategic vision of "thousands of tons of grain production consolidating and improving project" and guarantee the national food security, it is urgent to carry out the research of water resource system resilience of Hongxinglong Administration and thus to provide foundation for further water resource management in this region.

Data index and evaluation level

The water resource resilience of 12 farms in Hongxinglong Administration was evaluated based on AAF-PPC model, the monitoring data of evaluation index in 2011 were collected from Water Bureau of Hongxinglong
Administration in Heilongjiang province of China, of which there are no monitoring rainfall data of Baoshan Farm and Shuguang Farm, thus, in accordance with nearby principle, Baoshan Farm adopts the rainfall data of Jiangchuan Farm while Shuguang Farm adopts that of Beixing Farm.

According to the concept and characters of water resource system resilience and index acquisition condition and combining with the local situation(Yu 2007), the water resource system resilience index evaluation mechanism shall be established by the selection of 12 indexes including precipitation, forest coverage, population density, average per capita water resource, average per capita GDP, chemical fertilizer for the unit arable land, the proportion of effective irrigation area, proportion of agricultural water consumption, the ratio of agricultural output to GDP, proportion of irrigation area, quantity of electromechanical well in the unit arable land, and the total fund investment in water conservancy. The classification standard is set on the basis of the previous study and evaluation and the actual local situation (Sun et al. 2011), and detailed please see the Table 1.

Computing water resource system resilience

\section{Establish PPC model of the standard sample}

There were three evaluation levels (three evaluation samples) according to Table 1, there were 12 indexes every evaluation sample, belonging to $12 d$ data. In the process of adaptive artificial fish-swarm algorithm, population size $N=50$, artificial fish perception scope Visible $=1$,

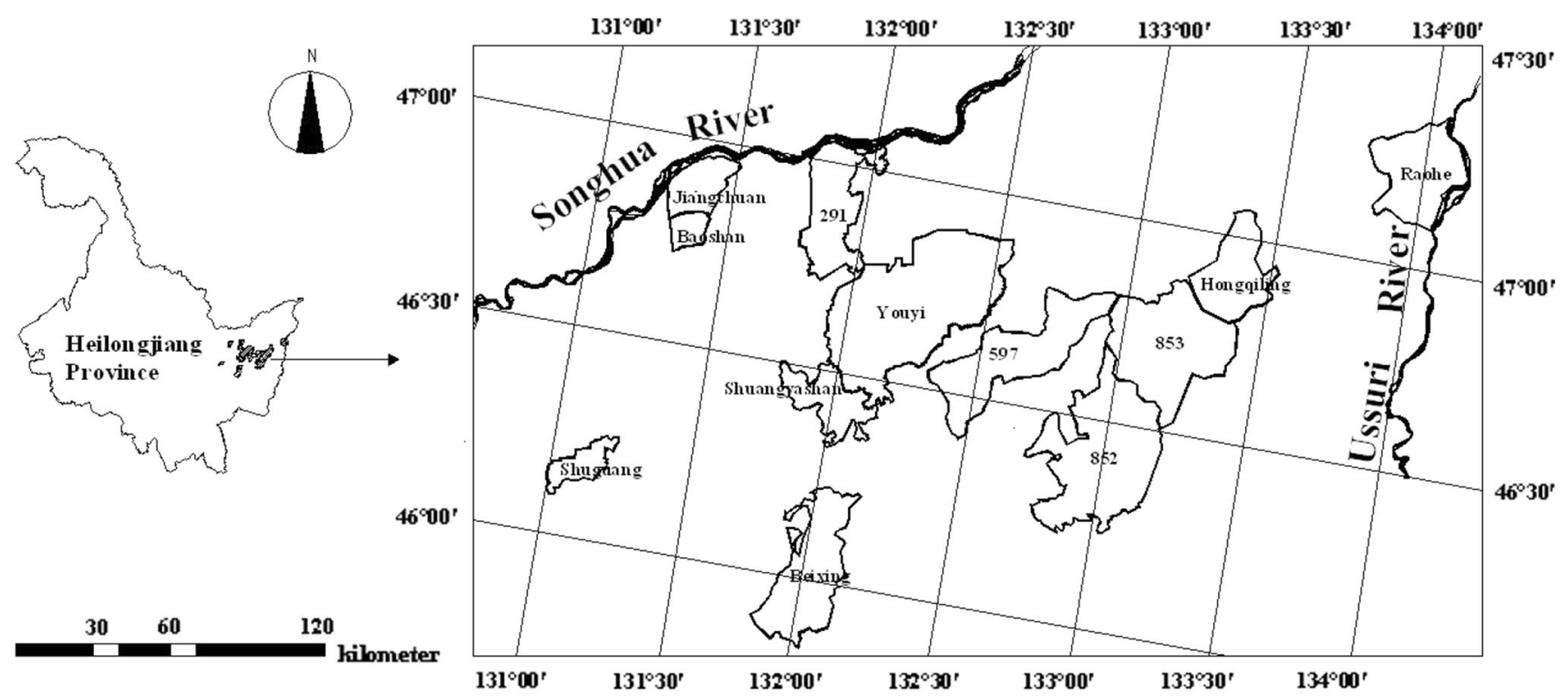

Fig. 1 Location of Hongxinglong administration in Heilongjiang Province, China 
Table 1 Level of evaluation index system of water resource system resilience in Hongxinglong administration

\begin{tabular}{|c|c|c|c|}
\hline Evaluation index & I & II & III \\
\hline Precipitation (mm) & $>45$ & $30-45$ & $<30$ \\
\hline Forest coverage $(\%)$ & $>40$ & $10-40$ & $<10$ \\
\hline $\begin{array}{l}\text { Population density } \\
\text { (per capita/ha) }\end{array}$ & $<30$ & $30-50$ & $>50$ \\
\hline $\begin{array}{l}\text { Average per capita water } \\
\text { resource }\left(\mathrm{m}^{3} / \text { per capita) }\right.\end{array}$ & $>8,000$ & $2,000-8,000$ & $<2,000$ \\
\hline $\begin{array}{l}\text { Average per capita GDP } \\
\left(10^{4} \text { yuan }\right)\end{array}$ & $>7$ & $4-7$ & $<$ \\
\hline $\begin{array}{l}\text { Proportion of effective } \\
\text { irrigation area }(\%)\end{array}$ & $>80$ & $30-80$ & $<30$ \\
\hline $\begin{array}{l}\text { Proportion of agricultural water } \\
\text { consumption }(\%)\end{array}$ & $<90$ & $90-95$ & $>95$ \\
\hline $\begin{array}{l}\text { The ratio of agricultural output } \\
\text { to GDP }(\%)\end{array}$ & $<30$ & $30-50$ & $>50$ \\
\hline $\begin{array}{l}\text { Proportion of irrigation area } \\
(\%)\end{array}$ & $<40$ & $40-70$ & $>70$ \\
\hline $\begin{array}{l}\text { Chemical fertilizer for the unit } \\
\text { arable land }(\mathrm{kg} / \mathrm{ha})\end{array}$ & $<300$ & $300-400$ & $>400$ \\
\hline $\begin{array}{l}\text { Quantity of electromechanical } \\
\text { well in the unit arable land } \\
\left(y a n / \mathrm{km}^{2}\right)\end{array}$ & $<2$ & $2-10$ & $>10$ \\
\hline $\begin{array}{l}\text { The total fund investment in } \\
\text { water conservancy }\left(10^{4} \text { yuan) }\right.\end{array}$ & $>5,000$ & $1,000-5,000$ & $<1,00$ \\
\hline
\end{tabular}

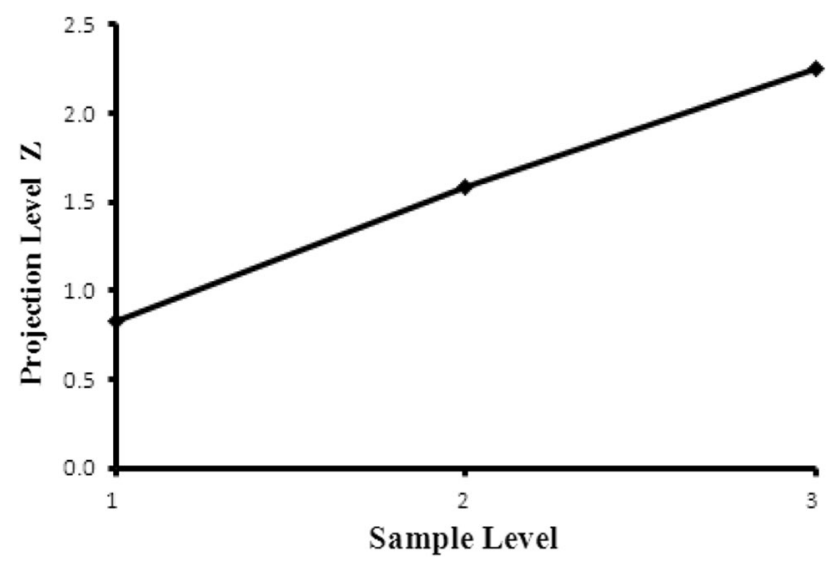

Fig. 2 Scatter diagram of projection value of standard sample of water resource resilience

moving step length Step $=0.5$, initial congestion level $\delta=0.3$, the largest number of test of each move Try number $=50$. It is concluded that the largest projection index of standard sample is 0.0313 , the best projection vector $a *=\{0.3075,0.3740,0.3975,0.2229,0.1690,0.1784$, $0.1221,0.3657,0.4151,0.1345,0.3955,0.0449\}$, projection value $z_{1}^{*}(j)=\{0.8305,1.5815,2.2517\}$. The result is shown in Fig. 2.

\section{Establish PPC model of the evaluation sample}

It is concluded that the largest projection index of evaluation sample is 0.7216 , the best projection vector $a *=$ $\{0.5517,0.2933,0.0971,0.4981,0.1773,0.0976,0.4094$, $0.5273,0.4625,0.2510,0.3817,0.1829\}$, projection value $z_{2}^{*}(j)=\{1.0931,0.7448,1.0629,1.6536,1.9920,1.3284$, $1.3725,1.7876,1.2313,0.9470,1.9959,1.4021\}$. The evaluation level could be received by comparing $z_{1}^{*}(j)$ with $z_{2}^{*}(j)$, the result is shown in Table 2 .

Using GIS, the distribution of water resource resilience in Hongxinglong Administration is given in Fig. 3.

According to the optimal projection direction, further analysis of the influence of various evaluation indexes on the comprehensive evaluation result can be conducted, and make sequence about the value of $a *$ and get three main indexes with larger contribution rate as: precipitation, proportion of agricultural water consumption, average per capita water resource.

\section{Establish RAGA-PPC model of the evaluation sample}

Apply RAGA-PPC for the evaluation of water resource resilience on those 12 farms and make comparison with AAFSA-PPC model. In the process of adaptive artificial fish-swarm algorithm, choose the parent initial population size $n=400$, crossover probability $p_{c}=0.8$, mutation probability $p_{m}=0.8,12$ selected outstanding individuals, $a$ $=0.05$, and the accelerating time is 20 . Calculate the projection value of the standard sample, it is concluded that the largest projection index is 0.1886 , the best projection

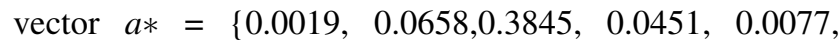
$0.1652,0.1900,0.4838,0.0498,0.5736,0.4261,0.1877\}$, projection value $z_{1}^{*}(j)=\{1.0386,1.2710,1.3549\}$. Calculate the projection value of evaluation sample, it is concluded that the largest projection index is 0.5718 , the best projection vector $a *=\{0.2376,0.0894,0.3041,0.2973$, $0.2074,0.2693,0.3726,0.4541,0.1557,0.2361,0.3801$, $0.2638\}$, projection value $z_{2}^{*}(j)=\{1.0616,0.7873,1.0597$, $1.5347,1.8180,1.4367,1.0477,1.6348,0.7798,0.9454$, $1.6811,1.2531\}$.

Table 2 Evaluation of water resource system resilience based on AAFSA-PPC Model in Hongxinglong administration

\begin{tabular}{|c|c|c|c|c|c|c|c|c|c|c|c|c|}
\hline Farm & Youyi & 597 & 852 & 853 & Raohe & 291 & Shuangyashan & Jiangchuan & Shuguang & Beixing & Hongqiling & Baoshan \\
\hline Value & 1.0931 & 0.7448 & 1.0629 & 1.6536 & 1.9920 & 1.3284 & 1.3725 & 1.7876 & 1.2313 & 0.9470 & 1.9959 & 1.4021 \\
\hline Level & I & I & I & II & III & II & II & II & II & I & III & II \\
\hline
\end{tabular}


Fig. 3 Spatial distribution maps of water resource resilience in Hongxinglong administration

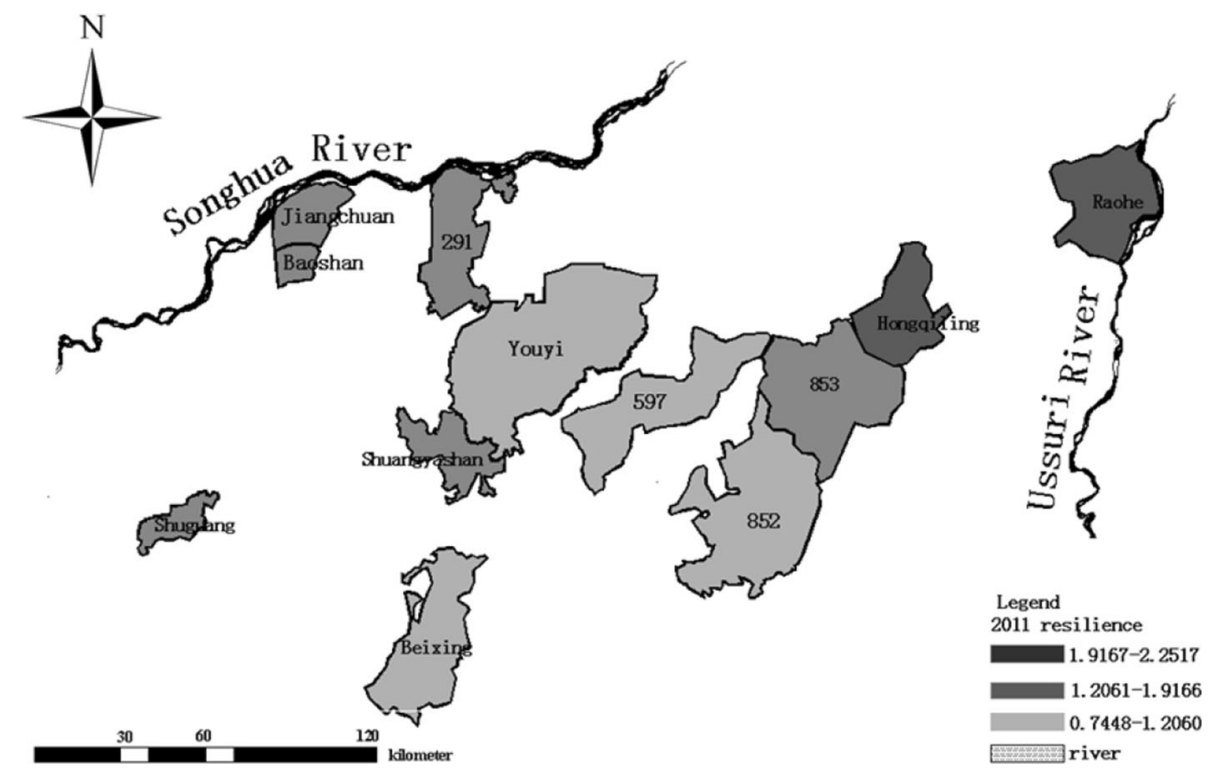

Table 3 Evaluation of water resource system resilience based on RAGA-PPC Model in Hongxinglong administration

\begin{tabular}{lllllllllllll}
\hline Farm & Youyi & 597 & 852 & 853 & Raohe & 291 & Shuangyashan & Jiangchuan & Shuguang & Beixing & Hongqiling & Baoshan \\
\hline Value & 1.0616 & 0.7873 & 1.0597 & 1.5347 & 1.8180 & 1.4367 & 1.0477 & 1.6348 & 0.7798 & 0.9454 & 1.6811 & 1.2531 \\
Level & I & I & I & III & III & III & I & III & I & I & III & II \\
\hline
\end{tabular}

The evaluation level could be received by comparing $z_{1}^{*}(j)$ with $z_{2}^{*}(j)$, the result is shown in Table 3 .

Using GIS, the distribution of water resource resilience in Hongxinglong Administration is given in Fig. 4.

According to the optimal projection direction, further analysis of the influence of various evaluation indexes on the comprehensive evaluation result can be conducted, and make sequence about the value of $a *$ and get three main indexes with larger contribution rate as: proportion of agricultural water consumption, proportion of irrigation area, quantity of electromechanical well in the unit arable land.

Results and discussion

According to the evaluation result from the improved AFSA, Raohe Farm and Hongqiling Farm have the strongest water resource resilience than Jiangchuan Farm, Baoshan Farm, 291 Farm, Shuangyashan Farm, Shuguang Farm and 853 Farm, and at last Youyi Farm, 597 Farm, 852 Farm and Beixing Farm. Entirely speaking, the water resource resilience of eastern area is the strongest than the northern and western area, and at last the middle area. The evaluation result conforms to the actual situation, and according to Fig. 1, there is Ussuri River in the east, Woken River in the west, and Songhua River in the north of Hongxinglong Administration, and farms close to rivers have a certain supplementation to the underground water, which promotes the resilience of water resource. From the collected data, the agricultural water consumption covers $90 \%$ that of the overall water consumption, of which Baoshan Farm reaches $99.76 \%$, so it requires all farms to save agricultural water consumption with introducing water-saving irritation technology. The annual rainfall data present that the rainfall of Raohe Farm reaches $511.2 \mathrm{~mm}$, Hongqiling Farm $456.3 \mathrm{~mm}$, and 597 Farm $261.6 \mathrm{~mm}$, and it is known that the rainfall is the key index influencing water resource resilience, which conforms to the actual information that rainfall directly affects the supplement of water resource and has a significant effect on water resource resilience of all regions. And compared with rainfall and agricultural water consumption, average per capita water resource is the least influencing factor: the average per capita water resource of Jiangchuan Farm reaches $11856.65 \mathrm{~m}^{3}$ while Shuangyashan Farm $495.82 \mathrm{~m}^{3}$. According to Table 2, the projection value of Jiangchuan Farm is 1.7876 while Shuangashan Farm 1.3725, which belongs to the same II degree. Thus, combining with agricultural water consumption (Jiangchuan Farm is $99.52 \%$ while Shuangyashan Farm 90.03 \%), it shows that the influence of average per capita water resource on water resource resilience is very small but still can not be ignored. The evaluation result of 12 farms in Hongxinglong Administration tells that the overall water 
Fig. 4 Spatial distribution maps of water resource resilience in Hongxinglong administration

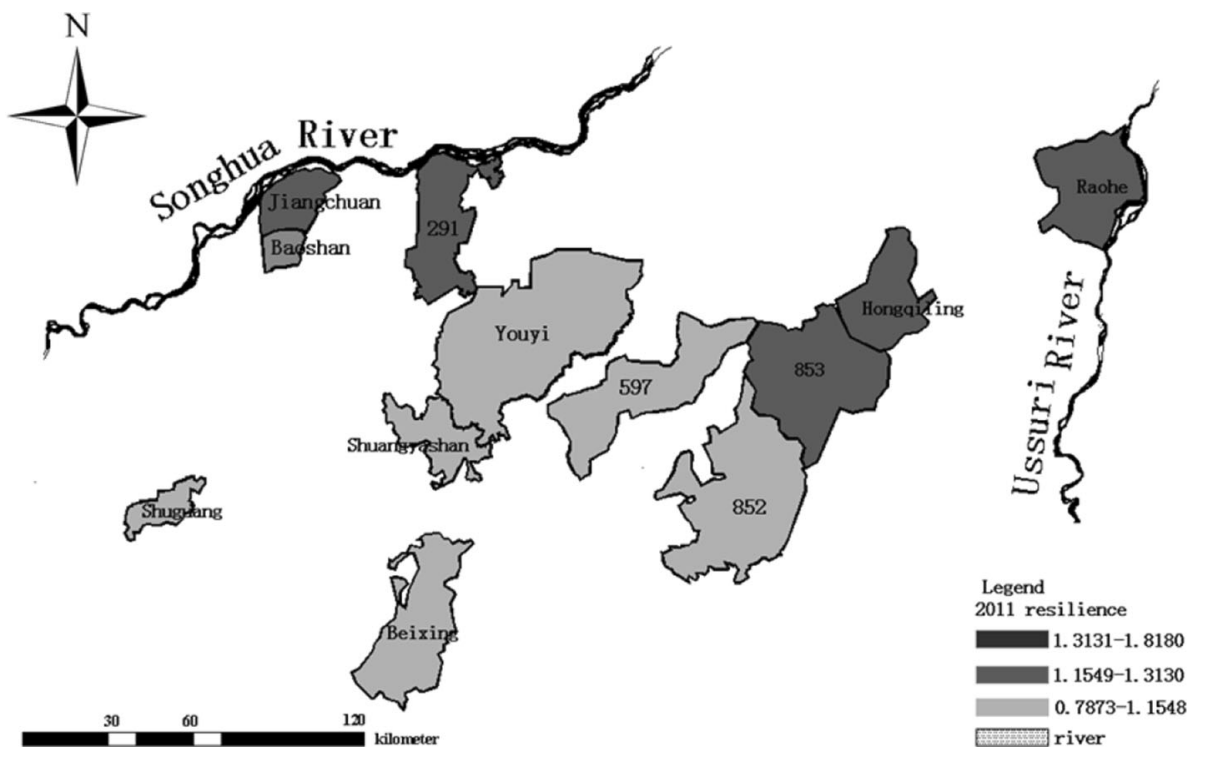

resource resilience situation needs to be worried. The water consumption of all farms is very large while the supplement is small, which causes the continuous decline of water resource with weak resilience capability. Thus, it can be seen that the water resource resilience capability is the result of the combined effects of evaluation indexes instead of the determination of single index on the resilience.

The evaluation result of accelerating genetic algorithm shows that the water resource resilience of 853 Farm, Raohe Farm, 291 Farm, Jiangchuan Farm, and Hongqiling Farm is the strongest than Baoshan Farm, and the last Youyi Farm, 597, 852 Farm, Shuangyashan Farm, Shuguang Farm and Beixing Farm. The overall tendency of water resource resilience is increasing from the west to the east. The calculation result presents that the main index influencing water resource resilience is agricultural water consumption proportion, the electromechanical wells in unit arable land, and the ratio of effective irrigation area. The collected information tells the agricultural water consumption of 853 Farm (III degree) is $99.37 \%$, the electromechanical wells in unit arable land are three wells per hectare, and the maximum ratio of effective irrigation area is $49.02 \%$; the agricultural water consumption of Baoshan Farm (II degree) is $99.76 \%$, the electromechanical wells in unit arable land are 15 wells per hectare, and the maximum ratio of effective irrigation area is $55.98 \%$; and the agricultural water consumption of Youyi Farm (I degree) is $99.32 \%$, the electromechanical wells in unit arable land are four wells per hectare, and the maximum ratio of effective irrigation area is $89.87 \%$. From the comparison of Youyi Farm and 853 Farm, if there is a little difference between agricultural water consumption ratio and the quantity of electromechanical well in unit arable land, the water resource resilience of the farm with large effective irrigation area is contrarily weak and the difference between the index contribution rate and evaluation grading is comparatively large, thus, the projection pursuit classification model on the improved AFSA is more suitable for the evaluation of regional agricultural water resource resilience with its evaluation result closer to the actual situation and faster program run rate.

Suggests of improving water resource system resilience

To improve the resilience situation of Hongxinglong Administration water resource system, analysis on water resource system resilience adaptability measures shall be conducted from the angle of key driving factor:

(1) Since it is difficult for artificial control of rainfall, rainwater harvesting technology can be used to store rainwater when the rainfall is large. Hongxinglong Administration now owns embankment miniature rainwater harvesting project (Sun et al. 2003) and large harvesting project of rainwater collection and distribution can be built (Hashim et al. 2013), thus to increase available water resource, supplement ground water resource, and improve the ability of water resource system resilience.

(2) Generally the irrigation in the agricultural production area is flush irrigation mode, so irrigation water-saving mode as alternate wetting and drying water-saving irrigation technique (Rejesus et al. 2011) should be used during the production, and technology management selection evaluation frame (Hess and Knox 2013) can be introduced to improve agricultural water consumption efficiency, reduce irrigation water consumption loss, and promote water resource utilization.

(3) Due to Hongxinglong Administration takes irrigation mainly in well irrigation, overexploitation of groundwater 
leads to the decline of groundwater level, less of surface water resources development and utilization and so on. To make use of surface water resources vigorously, the mode of draining-storing-irrigating can be used (Yan et al. 2008). Meanwhile, in the territory of Hongxinglong Administration, there are large, medium and small rivers of more than 30, the river surface area of 145,000 hectares, of which there are 19 rivers of drainage area of $200 \mathrm{~km}^{2}$, it is divided into two major river systems: Songhua River System and Ussuri River System. Songhua River System has eight rivers, Ussuri River has 11 rivers. Larger rivers are Naoli River, Inside and Outside Qixing River, Woken River, Anbang River in the region, Songhua River and Ussuri River through the territory of the region. Of with Naoli river through Beixing Farm, 597, 832, 853 Farm, Hongqiling Farm and Raohe Farm, it is importing into Ussuri River, Qixing River flows though Shuangyashan Farm, Youyi Farm, 597 and 859 Farm, it is importing into Naoli River. There are Jiangchuan Irrigation Area, Raohe Irrigation Area, Longtouqiao Irrigation Area in Hongxinglong Administration; the benefit units of irrigation area have Jiangchuan Farm, Baoshan Farm and Raohe Farm, 852 and 597 Farm. In addition, there are a large reservoir, three medium-sized reservoirs, 42 small reservoirs to supply water for agricultural production. It is known according to above information that much more water can be used by building irrigation district near rivers as Qixing River to supply water for Shuangyashan Farm, so the available amount of surface water resource increase and water system resilience can be improved.

\section{Conclusion}

- We introduce AAFSA to find up the optimization based on PPC Model. The results of assessment are that the water resource system resilience of Jiang chuan Farm, Hongqiling Farm, 853 Farm, and Raohe Farm are highest; the water resource system resilience of Youyi Farm, 597, 852, 291 Farm, Shuangyashan Farm, Shuguang Farm, Beixing Farm and Baoshan Farm is weaker. The reason why it engenders the result may be precipitation, water resource, proportion of agricultural water, population density etc.

(2) Projection Pursuit Classification Model based on AAFSA chooses 12 factors of evaluation to estimate influences on water resource system resilience to avoid the limitations of single index evaluation. The modified AFSA with self-adapting step and congestion level overcomes weakness of local optimization and improves the global search ability and convergence speed. We verify its feasibility by estimating influences on water resource system resilience of Hongxinglong Administration. The comprehensive evaluation conforms to the actual situation, provides a research mode for the effective management of the local water resource development and utilization and has certain reference value.

(3) The achievement provides a research mode for regional agricultural water resource system resilience study and offers scientific protection for the optimal utilization of water resource in Hongxinglong Administration. It also provides reference for our country to manage scientifically agricultural water resource in other regions in China.

Acknowledgments This study is supported by the National Natural Science Foundation of China (No. 41071053), Sub-Task of National Science and Technology Support Program for Rural Development in The 12th Five-Year Plan of China (No. 2013BAD20B04-S3), Special Fund of China Postdoctoral Science Foundation(No. 201003410), Specialized Research Fund for the Doctoral Program of Higher Education of China (No. 20102325120009), Sub-Task of Specialized Research Fund for the Public Welfare Industry of the Ministry of Water Resource (No. 201301096-0201), Natural Science Foundation of Heilongjiang Province of China (No. C201026), Specialized Research Fund for Innovative Talents of Harbin (Excellent Academic Leader) (No. 2013RFXXJ001), Postdoctoral Scientific Research Start-up Fund of Heilongjiang Province of China (No. LBH-Q11154) and Science and Technology Research Program of Education Department of Heilongjiang Province (No. 12531012).

Open Access This article is distributed under the terms of the Creative Commons Attribution License which permits any use, distribution, and reproduction in any medium, provided the original author(s) and the source are credited.

\section{References}

Chang J, Zhao XY (2013) Application of PPC model in the evaluation of water resources carrying capacity. Yellow River 35(9):71-73

Chang H, Jung IW, Strecker A et al (2013) Water supply, demand, and quality indicators for assessing the spatial distribution of water resource vulnerability in the Columbia River basin. Atmos Ocean 51(4):339-356

Chen S, Duan HM (2010) Quantitative assessment of socialecological systems resilience in Xining City. J Inner Mong Norm Univ (Natural Science Edition) 5(496-499):504

Comfort LK (1994) Risk and resilience: inter-organizational learning following the Northridge earthquake of 17 January 1994. J Contingencies Crisis Manag 2(3):157-170

Ding H, Liu D, Li T (2010) Projection pursuit model for evaluating drought based on improved artificial fish swarm algorithm of Sanjiang Plain. Trans CSAE 26(12):84-88

Friedman JH, Tukey JW (1974) A projection pursuit algorithm for exploratory data analysis. IEEE Trans Comput 23(9):881-890

Fu Q (2006) Data processing method and agricultural application. Science Press, Beijing

Hashim H, Hudzori A, Yusop Z et al (2013) Simulation based programming for optimization of large-scale rainwater harvesting system: Malaysia case study. Res Conserv Recycl 80:1-9

Hess TM, Knox JW (2013) Water savings in irrigated agriculture: a framework for assessing technology and management options to reduce water losses. Outlook Agricult 42(2):85-91 
Holling CS (1973) Resilience and stability of ecological systems. Annu Rev Ecol Syst 7(4):1-23

Jiang QX, Fu A, Wang ZL (2011) Comprehensive evaluation of regional land resource carrying capacity based on projection pursuit model optimized by particle swarm optimization. Trans CSAE 27(11):319-324

Li XL (2003) A new intelligent optimization method-artificial fish swarm algorithm. Zhejiang University, Hangzhou

Manfredi G, Rose A, Sapountzaki K et al (2014) Resilience and sustainability in relation to disasters: a challenge for future cities: common vision and recommendations//resilience and sustainability in relation to natural disasters: a challenge for future cities. Springer International Publishing, Switzerland, pp 77-79

Mehdi N, Ghodrat S, Mehdi S, et al. (2012) Artificial fish swarm algorithm: a survey of the state-of-the-art, hybridization, combinatorial and indicative applications. Artif Intell Rev pp 1-33

Perz SG, Muñoz-Carpena R, Kiker G et al (2013) Evaluating ecological resilience with global sensitivity and uncertainty analysis. Ecol Model 263:174-186

Rejesus RM, Palis FG, Rodriguez DGP et al (2011) Impact of the alternate wetting and drying (AWD) water-saving irrigation technique: evidence from rice producers in the Philippines. Food Policy 36:280-288

Shang YR, Chen JF, Zhang RQ et al (2011) Assessment framework and method of agricultural system resilience to drought - a case study of Xingtai City, Hebei Province. Chin J Eco Agricult 19(1):167-171

Shu DC, Fan ML, Lin SY (2004) Applying projection pursuit cluster based on immune evolutionary algorithm in groundwater regime classification. J Sichuan Univ 36(1):15-18
Sun DH, Sun FY, Wang EL (2003) The discussion on the water resource and nature environment in the Hongxinglong Bureau. Water Conserv Sci Technol Econ 9(4):272-273

Sun CZ, Hu DL, Yang L (2011) Recovery capacity of groundwater system in lower Liaohe River Plain. Adv Sci Technol Water Res 31(5):5-10

Vergano L, Nunes PALD (2007) Analysis and evaluation of ecosystem resilience: an economic perspective with an application to the Venice lagoon. Biodiv Conserv 16(12):3385-3408

Wang XY (2008) The adaptive cycle mechanism and versue arid resilience of rural social-ecological system in the loess plateau. Northwest University

Xie YL, Wang JH, Liang YZ et al (2005) Robust principal component analysis by projection pursuit. J Chemo Metrics 7(6):527-541

Yan BH, Yang YC, Yao ZC (2008) Discussion on IDDS the optimal water conservancy pattern in Heilongjiang Province. J Heilongjiang Hydraul Eng 35(3):55-59

Yu CS (2007) Quantitative assessment of water resource system resilience. J Hydraul Eng Suppl:495-499

Zhao Z (2009) Evaluation of the water resource system resilience supported by GIS based on the second Songhua River of Jilin Province. Northeast Normal University, Changchun

Zhao XY, Fu Q, Xing ZX (2007) Application of projection pursuit grade evaluation model in comprehensive evaluation of changes in soil quality. J Soil 44(1):164-168

Zhong W, Li TY (2012) Transmission net-work planning based on adaptive artificial fish school algorithm. Electr Eng 1:16-19 